\title{
Justification and Explanation in Mathematics and Morality
}

\author{
Justin Clarke-Doane
}

In an influential book, Gilbert Harman writes:

In explaining the observations that support a physical theory, scientists typically appeal to mathematical principles. On the other hand, one never seems to need to appeal in this way to moral principles.

(Harman 1977: 10)

What is the epistemological relevance of this contrast, if genuine? In this chapter, I argue that ethicists and philosophers of mathematics have misunderstood it. They have confused what I will call the justificatory challenge for realism about an area, D-the challenge to justify our D-beliefs-with the reliability challenge for D-realism-the challenge to explain the reliability of our D-beliefs. Harman's contrast is relevant to the first, but not, evidently, to the second. One upshot of the discussion is that genealogical debunking arguments are fallacious. Another is that indispensability considerations cannot answer the Benacerraf-Field challenge for mathematical realism.

\subsection{THE JUSTIFICATORY CHALLENGE}

Let the justificatory challenge for realism about an area, D, be the challenge to justify our D-beliefs (realistically construed). ${ }^{1}$ By "justify," I mean argue

${ }^{1}$ I will not consistently add the qualification "realistically construed" in what follows. But this is always intended. (Obviously, no argument supports or threatens our beliefs under any construal.) Realism about an area, D, is roughly the view that D-sentences should be interpreted literally, and that some atomic or existentially quantified ones are true relevantly counterfactually, constitutively, and causally independent of anyone's believing them to be. For a detailed explication of "D-realism," see Clarke-Doane (2012a: section 1). 
for, or defend. (I do not assume that being able to justify our belief that $\mathrm{p}$ is either necessary or sufficient for being justified in believing that p.) Then one answer to the justificatory challenge for mathematical realism is that the contents of our mathematical beliefs figure into the best explanation of our observations. By “observation," I mean any "immediate judgment made in response to the situation without any conscious reasoning" (Harman 1977: 208), where a judgment is a mental event, not a propositional content. Note that both mathematical and moral beliefs, understood in the occurrent sense, may qualify as observations. W. V. O. Quine writes:

Objects at the atomic level and beyond are posited to make the laws of macroscopic objects, and ultimately the laws of experience, simpler ... Moreover, the abstract entities which are the substance of mathematics ... are another posit in the same spirit. Epistemologically these are myths on the same footing with physical objects ... neither better nor worse except for differences in the degree to which they expedite our dealings with sense experiences.

(Quine 1951: 42)²

One advantage to Quine's answer to the justificatory challenge for mathematical realism is that it seems to afford an empirical justification of our mathematical beliefs (realistically conceived). By an "empirical justification," I mean an argument or defense that should convince an empirical scientific realist. In particular, one can argue that, merely by being an empirical scientific realist, one is committed, on pain of incoherence, to being a mathematical realist. As Hilary Putnam writes:

[Q] uantification over mathematical entities is indispensable for science ... therefore we should accept such quantification; but this commits us to ... the existence of the mathematical entities [that satisfy our theories]. This type of argument stems, of course, from Quine, who has for years stressed both the indispensability of quantification over mathematical entities and the intellectual dishonesty of denying the existence of what one daily presupposes.

(Putnam 1971: 347)

The drawback of Quine's answer to the justificatory challenge is that it seems to afford no way to justify all of our mathematical beliefs. It seems hopeless to argue that the contents of our higher set-theoretic beliefs figure into the best explanation of our observations, for example. Quine himself was compelled to pronounce such truths "mathematical recreation and without ontological rights” (Quine 1986: 400).

2 I am not sure whether Quine means the same thing by "sense experience" as Harman means by "observation," though their usage of these terms is clearly related. But I will be concerned with the Quinean position where "sense experience" means what Harman means by "observation." 
But however compelling Quine's answer to the justificatory challenge for mathematical realism may be, notoriously, a similar answer does not seem possible in the moral case. ${ }^{3}$ Gilbert Harman writes:

Observation plays a part in science it does not appear to play in ethics, because scientific principles can be justified ... by their role in explaining observations ...

(Harman 1977: 10)

In particular:

In explaining the observations that support a physical theory, scientists typically appeal to mathematical principles. On the other hand, one never seems to need to appeal in this way to moral principles.

(Harman 1977: 9-10)

Let the Indispensability Thesis be the claim that the contents of our typical mathematical beliefs figure into the best explanation of every observation (in Harman's sense), and let Harman's Objection be the claim that the contents of our moral beliefs do not figure into the best explanation of any of our observations. ${ }^{4}$ It will not matter for my purposes whether either claim is actually true. But what would be the epistemological upshot if they both were true?

One upshot is obvious. If the Indispensability Thesis and Harman's Objection were both true, and if Quinean empiricism were also true, then our mathematical beliefs would be justified, but our moral beliefs would not be. By "Quinean empiricism," I mean the view that our belief that $\mathrm{p}$ is justified if and only if $\mathrm{p}$ figures into the best explanation of our observations.

A more interesting epistemological upshot has been touched upon. If the Indispensability Thesis and Harman's Objection were both true, then we would seem to be able to empirically justify our typical mathematical beliefs (realistically construed), but could not so justify any of our moral

3 Of course, some ethicists have challenged this appearance-just as some philosophers of mathematics have challenged the appearance that the contents of our typical mathematical beliefs (realistically construed) figure into the best explanation of our observations. See, for example, Sturgeon (1985), Brink (1989), and Boyd (2003a, 2003b), in the moral case, and Chihara (1990), Field (1980, 1989), and Hellman (1989) in the mathematical.

${ }^{4}$ Why does anyone believe the Indispensability Thesis, so strongly formulated? Because typical (e.g., not higher-set-theoretic) mathematics seems to play a role in our empirical scientific theories that is like the role played in them by their logic. It is a background assumption, so that every explanation "will contain the axioms of number theory and analysis" (Steiner 1973: 61). (Harman's Objection is sometimes understood as the claim that the contents of our moral beliefs do not figure into the best explanation of intuitively "observable phenomena" more generally_including, e.g., the movements of planets. The argument which follows would work equally under this reading of "Harman's Objection.") 
beliefs. Again, it is hard to see how to be an empirical scientific realist while rejecting mathematical realism, but there is no apparent obstacle to being an empirical scientific realist while rejecting moral realism. ${ }^{5}$ This point is merely dialectical, however. Does anything else follow?

\subsection{GENEALOGICAL DEBUNKING ARGUMENTS}

An increasingly common suggestion is that (knowledge of) Harman's Objection-or a consequence of it-undermines our moral beliefs (realistically construed), and the Indispensability Thesis blocks an analogous argument in the mathematical case. ${ }^{6}$ Richard Joyce writes:

Nativism [the thesis that moral beliefs are evolutionarily innate] offers us a genealogical explanation of moral judgments that nowhere ... presupposes that these beliefs are true ... My contention ... is that moral nativism ... might well ... render [moral beliefs] unjustified ... In particular, any epistemological benefit-of-the-doubt that might have been extended to moral beliefs ... will be neutralized by the availability of an empirically confirmed moral genealogy that nowhere ... presupposes their truth.

(Joyce 2008: 216)

Harman's Objection implies that there is a "moral genealogy that nowhere ... presupposes" the truth of our moral beliefs. Hence, if "the availability" of such a genealogy will "render moral beliefs unjustified," then a fortiori so will Harman's Objection. ${ }^{7}$

Joyce's reasoning is of interest. If sound, then the upshot of Harman's Objection is not merely the dialectical one that we cannot empirically justify our moral beliefs (realistically construed), as we apparently can our mathematical ones. It is that we ought (epistemically) to give them up.

But how could Harman's Objection undermine our moral beliefs? Again, if Quinean empiricism were true, then, rather than undermining our moral

5 But see Clarke-Doane (2014: section 2). Note that it does not follow that we cannot justify our moral beliefs in any way. Traditional realists about both mathematics and morality have tended to justify their (epistemically basic) beliefs by appeal to their intuitive evidentness. See Gödel (1947) and Ross (1939) for classic arguments.

6 I will not consistently add the qualification "knowledge of," but this is always intended. Note that (knowledge of) information, E, undermines our belief that p only if $\mathrm{p}$ was antecedently justified.

${ }^{7}$ Joyce's argument strictly speaks of the truth of our moral beliefs, while Harman's Objection speaks of their contents. But if the contents of our moral beliefs fail to figure into the best explanation of any of our observations, then so does their truth, and vice versa, by (uncontroversial instances of) the T-schema. I will, therefore, mostly ignore the distinction between the contents of our beliefs and their truth in what follows. 
beliefs, Harman's Objection would show that they were never justified to begin with. But even if this were what Joyce intended to show, such an argument would have no traction with Joyce's primary targets_- "non-naturalist" moral realists - who explicitly accept Harman's Objection and so, of course, reject Quinean empiricism. ${ }^{8}$

The only promising answer to the question of how Harman's Objection could undermine our moral beliefs of which I am aware is suggested by the work of Sharon Street. ${ }^{9}$ She writes:

[T] he realist must hold that an astonishing [inexplicable] coincidence took placeclaiming that as a matter of sheer luck, evolutionary pressures affected our evaluative attitudes in such a way that they just happened to land on ... the true normative views ... [T] o explain why human beings tend to make the normative judgments that we do, we do not need to suppose that these judgments are true.

(Street 2008: 208-9, emphasis in original)

Let the reliability challenge for realism about an area, D, be the challenge to explain the reliability of our D-beliefs (realistically construed). Then I understand genealogical debunking arguments as follows. Harman's Objection (or a consequence of it) undermines our moral beliefs (realistically construed) by showing that the reliability challenge for moral realism is unanswerable. The assumption, familiar from Hartry Field, is that "our belief in a theory [is] undermined if ... it would [appear to] be a huge coincidence if what we believed about its subject matter were correct" (Field 2005: 77). What debunkers must add is that in order to relevantly explain the reliability of our D-beliefs (realistically construed), it is at least necessary to show that their contents figure into their best explanation. ${ }^{10}$

The Indispensability Thesis blocks a genealogical debunking argument against mathematical realism (where our elementary mathematical beliefs are Harmanian observations). Joyce writes:

There is some evidence that natural selection has provided humans with an inbuilt faculty for simple arithmetic ... [D]oes the fact that we have such a genealogical explanation of our simple mathematical beliefs serve to demonstrate that we are

${ }^{8}$ See Joyce (2006: ch. 6). In his (forthcoming), p. 17, Joyce seems not to appreciate this.

${ }^{9}$ I will discuss two answers which are suggested by Joyce's work in section 4.3.

10 I borrow the term "reliability challenge" from Schechter (2010), though I understand it in accord with Field (1989: 26). Unlike debunkers and Field (see section 4.7), Schechter does not believe that the apparent impossibility of explaining the reliability of our D-beliefs undermines them (realistically construed). He merely thinks that it "counts against" them. I believe that the interest of the reliability challenge for D-realism is greatly diminished if it is not supposed to undermine our D-beliefs (realistically construed). But I will not be concerned with Schechter's view. 
unjustified in holding these beliefs? Surely not, for we have no grasp of how [mathematical] belief[s] might have been selected for ... independent of [their] truth.

(Joyce 2006: 182) $)^{11}$

If it is assumed that such an argument not only blocks one way of showing that the reliability challenge for mathematical realism is unanswerable, but also suffices to answer that challenge, then it follows that showing that the contents of our D-beliefs figure into their best explanation is both necessary and sufficient for relevantly explaining their reliability. How plausible is this conclusion? In what follows, I consider the necessity and the sufficiency claims in reverse order.

\subsection{THE BENACERRAF-FIELD CHALLENGE}

The sufficiency claim is immediately suspect. The reliability challenge for mathematical realism is widely thought to seem unanswerable even given the Indispensability Thesis. Paul Benacerraf writes:

$[\mathrm{O}] \mathrm{n}$ a realist (i.e., standard) account of mathematical truth our explanation of how we know the basic postulates must be suitably connected with how we interpret the referential apparatus of the theory ... [But] what is missing is precisely ... an account of the link between our cognitive faculties and the objects known ... We accept as knowledge only those observations which we can appropriately relate to our cognitive faculties.

(Benacerraf 1973: 674, emphasis in original)

Benacerraf's concern stems from the view that if $\mathrm{X}$ knows that $\mathrm{p}$, then there obtains a causal relation between $\mathrm{X}$ and the subject matter of $\mathrm{p} .{ }^{12}$ This is

11 Clarke-Doane (2012a: section 3) argues, contra Joyce, that we can explain the usefulness of arithmetic beliefs in terms of corresponding first-order logical truths alone (and similarly in the case of geometry). But for the purposes of this chapter, I set this argument aside, and assume that Joyce is correct. (In his (forthcoming), Joyce responds that he, unlike Street, is "free to maintain that an explanation of the usefulness of the ancestral belief that $2+3=5$ in terms of first-order logic is nevertheless one that presupposes that our ancestors' arithmetic beliefs were true" (p. 8, fn. 7, emphasis in original). But I do not know what this means. Surely Joyce does not claim that arithmetic truths are first-order logical truths. In his (forthcoming), Joyce writes that he does "not have space here to argue against Clarke-Doane's complicated argument, so [he]'ll take the simple way out and point out that in [his] work the ... mathematics example is just that - a passing illustration - and if it fails then [he]'ll still confidently stand by the general claim [that his argument does not overgeneralize]." But in his (2006), Joyce writes: "the dialectic within which I am working here assumes that if an argument that moral beliefs are unjustified ... would by the same logic show that our belief that $1+1=2$ is unjustified ... this would count as a reductio ad absurdum" (Joyce 2007: 182, fn. 5). For more on overgeneralization, see fn. 29.

${ }^{12}$ See Benacerraf (1973: 671-3). 
different from the view that if X knows-let alone justifiably believes — that $\mathrm{p}$, then $\mathrm{p}$ figures into the best explanation of our "observation" that $\mathrm{p}$ (or figures into the best explanation of any of our observations, in Harman's sense). ${ }^{13}$ Benacerraf does not discuss the latter constraint, which is trivially satisfied in the mathematical case, by the Indispensability Thesis. As Mark Steiner writes:

[S] uppose that we believe ... the axioms of analysis or of number theory ... [S]omething is causally responsible for our belief, and that there exists a theory-actual or possible, known or unknown-which can satisfactorily explain our belief in causal style. This theory, like all others, will contain the axioms of number theory and analysis.

(Steiner 1973: 61, emphasis in original) $)^{14}$

Of course, causal constraints on knowledge and justification are now widely rejected. But the reliability challenge for mathematical realism still appears to be unanswerable. The problem is that it can appear impossible to explain the reliability of our mathematical beliefs, whether in terms of a causal relation between their subject matter and us or in any other way. Field writes:

Benacerraf's own formulation ... relies on a causal theory of knowledge ... [But $t$ ] he key point ... is that ... it seems hard to give any account of our beliefs about ... mathematical objects that doesn't make the correctness of the beliefs a huge coincidence.

(Field 2005: 77) $)^{15}$

${ }^{13}$ See Clarke-Doane (2014) and (forthcoming a). In fact, there is no plausible analogue of Benacerraf's concern in the moral case (Clarke-Doane 2014: section 3). There does obtain a causal relation between us and the subject matter (the values of the names and bound variables) of our moral beliefs. Their subject matter is the likes of people, actions, and events. One might respond that there does not obtain a causal relation between us and the subject matter of sentences like "Generosity is a virtue." But whether we ought to believe any sentence of the form "F-ness is G" on a face-value construal is just the problem of universals. If we ought, then there fails to obtain a causal relation between us and the subject matter of all manner of our beliefs-e.g., that red is a color, that force is the product of mass and acceleration, and that Beethoven's Fifth Symphony is in the key of $\mathrm{C}$ minor. If we ought not, then such examples are irrelevant. Either way, unlike our mathematical beliefs, our moral beliefs generate no new Benacerraf problem (a similar point applies if one takes apparent talk of "reasons" as ontologically committing). This point is widely missed. See, for example, Bengson (forthcoming) and Joyce (forthcoming: 9).

${ }^{14}$ A similar point can be made with respect to logic. Every logical truth is a consequence of every explanation at all. Hence, for any logical truth that we believe, p, p figures into the best explanation of our "observation" that p. But surely this truism does not suffice to answer the reliability challenge for logical realism.

${ }^{15}$ Note that Field does not challenge the Indispensability Thesis in this context. 
To be sure, some advocates of the Indispensability Thesis claim that the Indispensability Thesis answers the reliability challenge for mathematical realism. They claim that since mathematical knowledge is like theoretical empirical scientific knowledge, arrived at by way of an inference to the best explanation of our observations, then it is no more mysterious than the latter. On this view, the likes of numbers, sets, and tensors are not epistemically different from electrons. Mark Colyvan writes:

[L]et's take a ... charitable reading of the Field version of the [Benacerraf] challenge, according to which the challenge is to explain the reliability of our systems of beliefs ... Once the challenge is put this way, we see that Quine has already answered it: we justify our system of beliefs by testing it against bodies of empirical evidence.

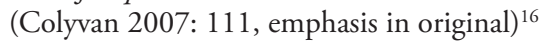

But this confuses the justificatory challenge and the reliability challenge. Showing that the contents of our mathematical beliefs figure into the best explanation of our observations - mathematical or otherwise-may help to empirically justify those beliefs. But it does not suffice to explain their reliability. It leaves it totally mysterious how those beliefs manage to reliability align with the mathematical truths (realistically construed). ${ }^{17}$ In general, showing that the contents of our D-beliefs figure into their best explanation is not sufficient for answering the reliability challenge for D-realism. Why, then, would debunkers assume that it is necessary?

\subsection{SENSITIVITY}

There are two reasons latent in the literature on debunking arguments. The first is that an explanation of the reliability of our D-beliefs would show that had the D-truths been different, our D-beliefs would have been correspondingly different. ${ }^{18}$

16 See also Hart (1996).

17 See also the quote from Field in section 4.7, as well as his (2005) where he writes: “[A]lthough [those who argue that Benacerraf's problem doesn't arise for the empiricist] say that empirical evidence bears on mathematical claims, they have not offered (and could not easily offer) even a clear sketch of how the experiences that allegedly might overturn our mathematics are reliable symptoms of the facts about mathematical objects" (Field 2005: 71). Colyvan claims not to fall prey to the above confusion, but I do not understand how he supposes himself to avoid it. Hart does not seem to acknowledge a distinction between justifying our beliefs and explaining their reliability.

${ }_{18} \mathrm{Or}$, more weakly, it would block the worry that had the D-truths been different, our D-beliefs would have failed to be (perhaps on the grounds that such counterfactuals are unintelligible). See Field (2005) and Clarke-Doane (2012a). The differences between the two demands will not matter for my purposes. 
For convenience, I will say that our D-beliefs are sensitive if this counterfactual is true. ${ }^{19}$ The assumption is that if the contents of our D-beliefs fail to figure into their best explanation, then they fail to be sensitive. Joyce writes:

Suppose that the actual world contains real categorical requirements- the kind that would be necessary to render moral discourse true. In such a world humans will be disposed to make moral judgments ... for natural selection will make it so. Now imagine instead that the actual world contains no such requirements at all-nothing to make moral discourse true. In such a world, humans will still be disposed to make these judgments ... for natural selection will make it so ... [D] oes the truth of moral judgments ... play a role in their usefulness? ... I believe the answer is "No."

(Joyce 2001: 163, emphasis in original) $^{20}$

The problem with such arguments is well-known. ${ }^{21}$ Suppose that our explanatorily basic moral beliefs_ — our conditional beliefs which purport to state the conditions under which a moral property is instantiated-are (actually) true, and that the explanatorily basic moral truths would be necessary if true at all. Then our explanatorily basic moral beliefs are vacuously sensitive on a standard semantics. Our non-basic moral beliefs seem to be sensitive even if the explanatorily basic moral truths would be metaphysically contingent. Had Bush's invasion of Iraq not been wrong, it would have been different in non-moral respects, and our moral beliefs would have varied correspondingly (since, even if the explanatorily basic moral truths would not be metaphysically necessary, the closest worlds in which the antecedent is true are presumably worlds in which those truths are the same). ${ }^{22}$ Note that neither conclusion depends on the claim that the contents (or truth) of our moral beliefs figure into their best explanation. ${ }^{23}$

19 Note that, while related, the present notion of sensitivity is different from that of Nozick (1981: ch. 3). Both notions must plausibly be relativized to a method of belief formation, though how they ought to be is irrelevant for my purposes.

${ }^{20}$ Similarly, Michael Ruse writes:

You would believe what you do about right and wrong, irrespective of whether or not a "true" right and wrong existed! The Darwinian claims that his/her theory gives an entire analysis of our moral sentiments. Nothing more is needed. Given two worlds, identical except that one has an objective morality and the other does not, the humans therein would think and act in exactly the same ways.

(Ruse 1986: 254)

And Walter Sinnott-Armstrong writes:

The evolutionary explanations [of our moral beliefs] work even if there are no moral facts at all.

(Sinnott-Armstrong 2006: 46)

${ }^{21}$ See Sturgeon $(1985,1986)$ for the basic insight.

22 Thanks to Alex Silk for helpful discussion of this point.

${ }^{23}$ Joyce no longer wishes to rely on such counterfactuals (see his (forthcoming)). Unfortunately, he does not seem to replace this reliance with an alternative answer to the 
Of course, the above argument assumes that our explanatorily basic moral beliefs are (actually) true. But this assumption is unobjectionable in the context of the reliability challenge, as debunkers themselves point out. ${ }^{24}$ Consider the perceptual case. What we can arguably offer in this case is an evolutionary explanation of how we came to have sensitive mechanisms for perceptual belief, and a neurophysical explanation of how those mechanisms work such that they are sensitive. ${ }^{25}$ But these explanations blatantly assume the (actual) truth of our explanatorily basic perceptual beliefs. If the reliability challenge for D-realism requested an explanation of the reliability of our D-beliefs which failed to assume the (actual) truth of our explanatorily

question at issue - or, correlatively, an alternative answer to the question of how Harman's Objection could undermine our moral beliefs. In his most recent work, he says that moral nativism shows that our moral beliefs are the product of a "non-truth-tracking" process which is "independent of their truth." But by this he just means that the contents of our moral beliefs do not figure into the best explanation of our having them (forthcoming: 8). In other words, Joyce simply repeats the relevant consequence of Harman's Objection, and does nothing to explain how it could "render moral beliefs unjustified." Similarly, in his (2006), he makes an argument by analogy. He claims that learning the truth of moral nativism is like learning that we have taken a "Napoleon lost Waterloo" pill (2006: 179). But, as Joyce apparently now recognizes, this case is not analogous. By all accounts, whether Napoleon lost at Waterloo is metaphysically contingent. Hence, there is no problem arguing that, had Napoleon won there, we still would have believed that he had lost.

24 See Balaguer (1995), Field (1989: 26) and the quotation from this page in section 4.7, Gibbard (2003: section 13), Schechter (2010), and Street (n.d.) for discussion of this issue. (Field, Gibbard, and Street add that, while any explanation of reliability will be "circular" in the present sense, adequate explanations must meet a non-triviality constraint. My own view is that once the challenge to explain the reliability of our abductive methodology is properly distinguished from the challenge to explain the reliability of our epistemically basic mathematical or moral beliefs, this suggestion cannot be made out. Only Field (1996: 371) ventures a statement of the needed constraint, but ends up just restating the sensitivity constraint at issue in this section. For my purposes here, however, all that matters is that the explanation of the sensitivity of our uncontroversial beliefs will be "circular.")

${ }_{25}$ See Schechter (2010) for something like this distinction of explanatory tasks. According to Schechter, such a distinction is important because the question of how we came to have a reliable mechanism for D-belief may remain open even under the assumption that it is unintelligible to imagine the D-truths being different (even if the question of how that mechanism works such that it is reliable may not). But I believe that this is mistaken. Schechter is explicit that the question of how we came to have a reliable mechanism for D-belief is different from the question of how we came to have the mechanism for D-belief that we actually came to have (since the latter question is clearly answerable in principle). However, in order to decide whether we were, say, selected to have a reliable mechanism for D-belief, as opposed to being selected to have a mechanism for D-beliefs with property, $\mathrm{F}$, that is in fact reliable, we would seem to need to have to decide what mechanism it would have benefited our ancestors to have had had the D-truths been different. For discussion, see Clarke-Doane (2012a, forthcoming a), and Field (2005). 
basic D-beliefs, then the apparent impossibility of answering it could not be thought to undermine those beliefs.

In order for the argument for the sensitivity of our explanatorily basic moral beliefs to work, it must also be assumed that the explanatorily basic moral truths would be metaphysically necessary (again, the argument for the sensitivity of our non-basic moral beliefs seems to work even without this assumption). But debunkers have typically allowed that they would be, and it is clear why. The belief that the explanatorily basic moral truths would be metaphysically necessary is commonly thought to have a similar status as the belief that they are (actually) true. It is a (defeasibly) justified belief that must be undermined. If debunkers merely claimed to undermine our moral beliefs under the assumption that the belief that the explanatorily basic moral truths would be metaphysically necessary is not itself (defeasibly) justified, then the interest of their argument would be greatly diminished.

In fact, debunkers tend to allege that whether the explanatorily basic moral truths would be metaphysically necessary is irrelevant. Even if there are no metaphysically possible worlds in which those truths are different, debunkers claim that the counterfactual, "had the explanatorily basic moral truths been different, our moral beliefs would have been correspondingly different," is not vacuously true. It must be evaluated with respect to "conceptually possible" worlds-where these are, roughly, ways the world could be, for all that we can intelligibly imagine. The explanatorily basic moral truths could have been different as a matter of "conceptual possibility." Speaking of normative truths generally, Street writes:

As a purely conceptual matter ... normative truths might be anything ... Noting this sense in which the normative truth might be anything, and noting the role of evolutionary forces in shaping the content of our basic evaluative tendencies, we may wonder whether ... it somehow promoted reproductive success to grasp the independent normative truth, and so creatures with an ability to do so were selected for. Unfortunately for the realist ... to explain why human beings tend to make the normative judgments that we do, we do not need to suppose that these judgments are true.

(Street 2008: 208)

The problem with this allegation is that we seem to be equally unable show that our beliefs which are not supposed to be in doubt in this context are sensitive with respect to "conceptually possible worlds." Consider our beliefs about ordinary objects, such as rocks. Street is explicit that her argument does not threaten realism about ordinary objects such as these. She writes:

[Evolutionary debunking arguments do not] go through against realism about nonevaluative facts such as facts about fires, predators, cliffs, and so on ... In order to 
explain why it proved advantageous to form judgments about the presence of fires, predators, and cliffs, one will need to posit in one's best explanation that there were indeed fires, predators, and cliffs, which it proved quite useful to be aware of, given that one could be burned by them, eaten by them, or could plummet over them.

(Street 2006: 160, fn. 35)

But even if the contents of our ordinary object beliefs figure into their best explanation, we do not seem to be able to show that our explanatorily basic ones are sensitive with respect to "conceptually possible worlds." While it may be metaphysically necessary that the conditions under which the property of being a rock is instantiated are what they are, it seems that they could have been different "as a purely conceptual matter." That they are is just what some ontologists allege. These ontologists allege that particles arranged rockwise fail to compose a rock. ${ }^{27}$ But had-for all that we can intelligibly imagine- this been the case, our rock beliefs would have been the same. ${ }^{28}$

The mathematical case makes the point vividly. By the Indispensability Thesis, the contents of our typical mathematical beliefs figure into the best explanation of every observation. But it is commonly held that, even if the Indispensability Thesis is true, virtually none of our mathematical beliefs is sensitive with respect to "conceptually possible" worlds. ${ }^{29}$ In fact,

26 We seem to be able to show that our non-basic moral beliefs are sensitive with respect to conceptually possible worlds for the same reason that we seem to be able to show that they are sensitive with respect to metaphysically possible ones. The closest worlds in which the non-basic moral truths are different are presumably still worlds in which the explanatorily basic moral truths are the same.

27 See Van Inwagen (1990) and Merricks (2001). See also Clarke-Doane (2014: section 3), and Berker (2014: section 8).

28 This shows that the widely assumed view that we were "selected to have true ordinary object beliefs," but not true moral beliefs, is obscure at best. For virtually any area, $\mathrm{D}$, had the explanatorily basic D-truths been different, it would have benefited our ancestors to have correspondingly different D-beliefs_-given the (actual) truth of our D-beliefs and that this counterfactual is evaluated with respect to metaphysically possible worlds. For virtually any area, D, the explanatorily basic D-truths would be metaphysically necessary, so the counterfactual is (vacuously) true. In particular, if D is morality, then the counterfactual is true. However, for virtually any area, D, the counterfactual is false if it is evaluated with respect to "conceptually possible" worlds. For virtually no D-truths would be conceptually necessary in the sense in question. In particular, the counterfactual is false if $\mathrm{D}$ is ordinary object discourse, as explained above. (Again, had the non-basic D-truths been different, it would have benefited our ancestors to have correspondingly different D-beliefs_-given the (actual) truth of our D-beliefs_- whether this counterfactual is evaluated with respect to metaphysically or conceptually possible worlds. In particular, this is true when D is morality, as explained above.)

29 See Azzouni (1994: 56), Balaguer (1999: 113), Ellis (1990: 113), Horgan (1987: 281), and the quotation from Field below. 
problematically, Field sometimes suggests that this is the Benacerraf problem. He writes:

The Benacerraf problem ... seems to arise from the thought that we would have had exactly the same mathematical ... beliefs even if the mathematical ... truths were different ... and this undermines those beliefs ... [T] here is a reasonably clear content (at least prima facie) to [this counterfactual]; that's what gives the Benacerraf problem its initial bite in the mathematical case.

(Field 2005: 81)

Merely arguing that the contents of our mathematical beliefs figure into their best explanation does nothing evidently to block this counterfactual. It "gives no sense to the idea that if the ... facts had been different then our ... beliefs would have been different too" (Field 1996: 371). ${ }^{30}$

To sum up: our moral beliefs appear to be sensitive with respect to metaphysically possible worlds, even if their contents do not figure into their best explanation - and reflection on the ordinary object and mathematical cases suggests that our explanatorily basic ones would fail to be sensitive with respect to "conceptually possible" worlds even if their contents did so figure. Hence, even if showing that our D-beliefs are sensitive is necessary for "explaining their reliability," this is no reason to assume that showing that our D-beliefs figure into the best explanation is necessary for explaining their reliability. What of the second reason to assume this?

\subsection{SAFETY}

The second reason is harder to pin down, but is suggested by Charles Darwin himself. He writes:

In the same manner as various animals have some sense of beauty, though they admire widely different objects, so they might have a sense of right and wrong, though led by it to follow widely different lines of conduct. If, for instance ... men were reared under precisely the same conditions as hive-bees, there can hardly be a doubt that our unmarried females would, like the worker-bees, think it a sacred duty to kill their brothers, and mothers would strive to kill their fertile daughters, and no one would think of interfering. Nevertheless the bee, or any other social animal, would in our supposed case gain ... some feeling of right and wrong, or a conscience.

(Darwin 1871: 70)

30 There is an argument from the Indispensability Thesis to the sensitivity of our mathematical beliefs with respect to "conceptually possible" worlds. But it is highly suspect. See Field (1989: 18-20) and Clarke-Doane (2012a). 
More recently, Michael Ruse writes:

Had evolution taken us down another path, we might well think moral that which we now find horrific, and conversely. This is not a conclusion acceptable to the [moral realist].

(Ruse 1986: 254)

It is tempting to read Darwin and Ruse as merely noting that had our explanatorily basic moral beliefs been different, they would have been false. ${ }^{31}$ But this counterfactual is a trivial consequence of moral realism. It says that the moral truths do not counterfactually depend on our moral beliefs. No explanation of the reliability of our moral beliefs (realistically construed) should counter this.

A more charitable reading of Darwin and Ruse adds that we could have easily had different explanatorily basic moral beliefs. The conclusion would then be that we could have easily had false moral beliefs. If we say that our D-beliefs are safe just in case we could not easily have had false ones, then it follows that our moral beliefs are not safe. ${ }^{32}$ The second reason may then be understood as the claim that an explanation of the reliability of our moral beliefs would show that they are safe.

But showing that the contents of our D-beliefs figure into their best explanation is not necessary for showing that they are safe as genealogical debunking arguments illustrate. Street's point is naturally taken to be that we were (all but) bound to have at least the "core" moral beliefs that we do have, whether or not they were true. To take a simple example, it does not seem that we could have easily believed that killing our offspring is good, since creatures who did would seem to have been less effective at passing on their genes than creatures believed what we do. Street writes, "among our most deeply and widely held judgments, we observe many ... with exactly the sort of content one would expect if the content of our evaluative judgments had been heavily influenced by selective pressures" (Street 2006: 116). But if we could not have easily had different "core" moral beliefs, then, given that our core moral beliefs are (actually) true and that the explanatorily basic moral truths would be necessary, at least our core moral beliefs could not have easily been false. Of course, showing that our "core" moral beliefs are safe is a far cry from showing that our moral beliefs generally are. ${ }^{33}$ But

${ }^{31}$ It must be our explanatorily basic beliefs that are in question since, again, had our non-basic beliefs been different, they would not plausibly have been false (given their actual truth).

${ }^{32}$ Again, a method of belief formation must plausibly be held fixed. But how exactly it ought to be is irrelevant for my purposes, so I ignore this complication. (Note that the present formulation of safety avoids the consequence that beliefs in necessary truths are automatically safe. See Pritchard (2008) for a related treatment.)

33 There is an argument that if our "core" moral beliefs are safe, then our moral beliefs generally are as safe as our beliefs from any area are. See Clarke-Doane (2012b: section 3). 
what matters is whether showing that our moral beliefs are safe requires showing that their contents figure into their best explanation. It clearly does not.

In fact, showing that the contents of our moral beliefs figure into their best explanation does not even seem to suffice to establish their safety. The appeal of pluralist accounts of mathematics, such as Mark Balaguer's "Full-Blooded Platonism," according to which every (consistent) mathematical theory is equally true (under a face-value Tarskian truth definition), is arguably that our mathematical beliefs would not be safe if (non-pluralist) standard mathematical realism were true. ${ }^{34}$ Even if we could not have easily believed that $1+1=3$, or that addition is not commutative, arithmetic trivialities wildly underdetermine the content of our mathematical theories. The Indispensability Thesis does nothing evidently to show that our mathematical beliefs are suitably constrained. Field writes:

[Pluralists solve] the [Benacerraf] problem by articulating views on which though mathematical objects are mind independent, any view we had had of them would have been correct ... [T] hese views allow for ... knowledge in mathematics, and unlike more standard [realist] views, they seem to give an intelligible explanation of it.

(Field 2005: 78) $)^{35}$

A similar point applies to ordinary objects. A common motivation for "mereological permissivism" is that our ordinary object beliefs would not be safe if standard mereological realism were true. Korman writes:

Proponents of sufficiently permissive conceptions ... can admit that we could easily have come to have slightly or radically different conventions, and that we would then have judged there to be various kinds of extraordinary objects. But our beliefs are nonetheless safe: whichever conventions we had ended up with, our judgments about the existence of the relevant objects would still have been correct. The extraordinary objects are all already out there waiting to be noticed; all that our conventions do is determine which ones we do notice.

(Korman 2011: section 4.2, emphasis in original) $)^{36}$

${ }^{34}$ See Clarke-Doane (forthcoming a: section 3). The relevant notion of consistency is a primitive modal one.

35 This is awkward, since, in the same section Field claims that the Benacerraf problem is the problem of showing that our mathematical beliefs are sensitive. But mathematical pluralism does nothing to help with this. Had- "as a purely conceptual matter"Balaguer's pluriverse failed to exist, or had it been different, our mathematical beliefs would have been the same. Indeed, Balaguer concedes that "[i]f there were never any such things as [mathematical] objects, the physical world [and, hence, our mathematical beliefs] would be exactly as it is right now" (Balaguer 1999: 113).

${ }^{36}$ Similarly, an earlier draft of Korman (2014) — which, coincidentally, is premised on the thesis that I am challenging here-contained the following quotations from Heller, Sider, and Hawthorne on pp. 1-2:

[I]f we conceptually divide up the world into objects one way rather than another because doing so will serve our purposes better [which we do], then there is little chance 
Again, merely arguing that the contents of our explanatorily basic ordinary object beliefs figure into their best explanation does nothing evidently to show that they could not have easily been different.

To sum up: debunking arguments themselves show that our moral beliefs may be safe, even if their contents fail to figure into their best explanation-and reflection on the ordinary object and mathematical cases suggests that they may fail to be safe even if their contents do so figure. Hence, even if showing that our D-beliefs are safe is necessary for relevantly explaining their reliability, this is no reason to assume that showing that our D-beliefs figure in the best explanation is necessary for explaining their reliability. Is there any other reason to assume this?

\subsection{MODAL SECURITY}

There is still the intuition that if the contents of our moral beliefs failed to figure into their best explanation, then those beliefs would "have nothing to do with" the moral truths (realistically construed) ${ }^{37}$ But stripped of its connection with sensitivity or safety, what could this mean? It could just amount to a restatement of Harman's Objection (or a consequence of it). ${ }^{38}$ But, in that case, the intuition cannot be used to explain how Harman's

that the resulting ontology will be the true ontology ... In principle, we could by sheer coincidence arrive at the true ontology by the use of conventions ... I will discount the possibility of such a coincidence.

(Heller 1990: 44)

On [a conservative) view, the entities that exist correspond exactly with the categories for continuants in our conceptual scheme: trees, aggregates, statues, lumps, persons, bodies, and so on. How convenient! It would be nothing short of a miracle if reality just happened to match our conceptual scheme in this way.

(Sider 2001: 156-7)

Barring a kind of anti-realism that none of us should tolerate, wouldn't it be remarkable if the lines of reality matched the lines that we have words for? The simplest exercises of sociological imagination ought to convince us that the assumption of such a harmony is altogether untoward, since such exercises convince us that it is something of a biological and/or cultural accident that we draw the lines that we do.

(Hawthorne 2006: 109)

Note that, unlike mathematical pluralism, mereological permissivism only "vindicates" positive beliefs of the relevant sort. It does not, for instance, vindicate the belief that there are not any "incars" - cars that are, necessarily, located in garages.

${ }^{37}$ Debunking arguments are often formulated in such a way as to leave this intuition unanalyzed. See Street (2006).

38 The claim that there is no "explanatory connection" between our moral beliefs and their contents (or truth) is an example of this suggestion. Again, this seems to be Joyce's in his (forthcoming). See n. 23. 
Objection undermines our moral beliefs. Alternatively, it could amount to the claim that there is no causal relation between the subject matter of our moral beliefs and us. But, in that case, it just replays Benacerraf's original argument, and cannot be thought to undermine our moral beliefs. ${ }^{39}$ Finally, it could amount to the claim that the probability that our moral beliefs are true is low. ${ }^{40}$ But either the probability at issue is epistemic or it is objective. If the probability is epistemic, then the suggestion is blatantly question-begging. It effectively amounts to the conclusion that debunking arguments are supposed to establish - that our moral beliefs are not justified. Suppose, then, that the probability is objective. Then for any (explanatorily basic) moral truth, $\mathrm{p}$, presumably $\operatorname{Pr}(\mathrm{p})=1$, given that such truths would be metaphysically necessary. ${ }^{41}$ Moreover, as genealogical debunking arguments themselves illustrate, it may be that $\operatorname{Pr}($ we believe that $\mathrm{p}) \approx 1$, because the probability of our having the (explanatorily basic) moral beliefs that we do is high. But, then, $\operatorname{Pr}(\mathrm{p} \&$ we believe that $\mathrm{p}) \approx 1$, by the probability calculus. Since, $\operatorname{Pr}($ our belief that $\mathrm{p}$ is true $)=\operatorname{Pr}(\mathrm{p} \&$ we believe that $\mathrm{p})$, it appears that $\operatorname{Pr}($ our belief that $\mathrm{p}$ is true $) \approx 1$, contrary to hypothesis. ${ }^{42}$

I suggest that debunkers' key assumption - that in order to relevantly explain the reliability of our D-beliefs it is at least necessary to show that their contents figure into their best explanation-is not just unsupported: it is dubiously coherent. I have argued that-assuming that our moral beliefs are actually true-we may be able to show that they are both sensitive and safe (in whatever sense we can show that our uncontroversial beliefs are), even given that their contents fail to figure into their best explanation. If debunkers' key assumption were correct, we may be unable to "explain the reliability" of our moral beliefs despite being able to show that they were (all but) bound to be true. Of course, there are surely senses of the quoted phrase in which this is true (there are myriad senses of "explain the reliability"). But the relevant sense of this phrase is such that the apparent impossibility of explaining the reliability of our D-beliefs undermines them (realistically construed). If debunkers' key assumption were correct, then

39 Again, this suggestion appears to be confused anyway. See n. 13.

${ }^{40}$ See Street (n.d.) for an apparent example of this suggestion.

${ }^{41}$ What if we only assign objective probability 1 to contents which are necessary in an even stronger sense-e.g., "conceptually necessary"? Then, again, the contents of our uncontroversial beliefs-e.g., our explanatorily basic ordinary object beliefs—would seem to have equal claim to being objectively improbable. See section 4.4. (Thanks to David James Barnett for discussion.)

${ }_{42}$ Perhaps the quoted phrase means that the truth of our belief that $\mathrm{p}$ is not "grounded in" or "constituted by" the fact that p (see Bengson (forthcoming) for something like this proposal)? Such hyperintensional ideology does not seem to me to be more perspicuous than the quoted phrase itself. But, even if it were, this proposal could not serve debunkers' dialectical purposes, as will become clear below. 
we may be obligated to give up beliefs which we can show were (all but) bound to be true.

How could that happen? That it could not is the key idea behind the following.

Modal Security: Information, E, cannot undermine our D-beliefs without giving us some reason to believe that our D-beliefs are not both safe and sensitive. ${ }^{43}$

Modal Security states a necessary condition on E. It does not say that if $\mathrm{E}$ gives us some reason to believe that our D-beliefs are not both safe and sensitive, then $\mathrm{E}$ undermines those beliefs. It says that if $\mathrm{E}$ does not even do this, then E cannot be thought to undermine them.

This principle is weak. It is plausible that $\mathrm{E}$ cannot undermine our D-beliefs without giving us some reason to believe that our D-beliefs are not safe-i.e., without giving us some reason to believe that, even if our D-beliefs are actually true (as we assume, for the sake of argument, in the moral case), we might have easily had false ones. Even if this is incorrect, it is hard to see how E could undermine our D-beliefs without giving us some reason to believe either that our D-beliefs are not safe or that they are not sensitive. ${ }^{44}$ If $\mathrm{E}$ fails to give us some reason to believe either of these things, then $\mathrm{E}$ fails to threaten our judgment that our D-beliefs were (all but) bound to be true. How could information obligate us to give up our beliefs of a kind while failing to threaten our judgment they were (all but) bound to be true?

It might be thought that Modal Security has absurd implications. Suppose that we are astrological realists. If we are granted the (defeasible) justification and (actual) truth of our astrological beliefs, and we can argue both that the explanatorily basic astrological truths would be necessary if true at all and that we could not have easily had different explanatorily basic astrological beliefs, then, by Modal Security, we can relevantly explain their reliability. That is, we can explain their reliability in any sense which is such that the apparent impossibility of explaining their reliability undermines them. Of course, it is doubtful that we could argue these things. But would it be a reductio of Modal Security if we could? Arguably, it would be a reductio of the idea that we should be granted the (defeasible) justification and

43 This principle is introduced in Clarke-Doane (forthcoming a). Again, sensitivity and safety must plausibly be relativized to methods of belief formation. (Thanks to David James Barnett for extensive discussion of this and related principles.)

44 "Rebutting" as well as "undercutting" underminers satisfy Modal Security. If E is evidence for (the contents of) alternative D-beliefs, then $\mathrm{E}$ is evidence that our D-beliefs are false and so, a fortiori, not both safe and sensitive. (Thanks to Sinan Dogramaci for helpful discussion of these issues.) 
(actual) truth of our astrological beliefs. If we are not granted these things, then there may be no hope of a dialectically effective argument against our position. But absent an answer to the question above, such an argument does not, in general, seem possible. If Modal Security is true, then debunking arguments overreach. ${ }^{45}$

\subsection{JUSTIFICATION AND EXPLANATION}

If Modal Security is true, then it is false that we must show that the contents of our moral beliefs figure into their best explanation in order to relevantly explain their reliability. It suffices to show that our moral beliefs are both safe and sensitive, and, as we have seen, in order to show this, we need not show that their contents figure into their best explanation. ${ }^{46}$

But even absent an argument that debunkers' key assumption is false, I hope to have shown that the positive arguments that it is true are poor. Why, then, have so many philosophers supposed otherwise? I suggest that, like some advocates of the Indispensability Thesis, they have confused the justificatory and reliability challenges for realism about an area. Field writes:

[W] can formulate [Benacerraf's] challenge so as to make indispensability considerations of questionable relevance to answering it. The way to understand Benacerraf's challenge ... is not as a challenge to ... justify our mathematical beliefs, but as a challenge to ... explain the reliability of these beliefs. We start out by assuming the existence of mathematical entities that obey the standard mathematical theories; we grant also that there may be positive reasons for believing in those entities. These positive reasons might ... be that the postulation of these entities appears to be indispensable ... But Benacerraf's challenge ... is to ... explain how our beliefs about these remote entities can so well reflect the facts about them ... [I]fit appears in principle impossible to explain this, then that tends to undermine the belief in mathematical entities, despite whatever reason we might have for believing in them.

(Field 1989: 26, emphasis in original)

I take Field to suggest that the challenge to empirically justify our mathematical beliefs should not be confused with the challenge to explain their reliability. Some explanations of the reliability of our mathematical beliefs-such as Balaguer's - fail to empirically justify them, since they fail to imply that their contents figure into the best explanation of any of our observations (though, again, Balaguer's view is consistent with this). ${ }^{47}$ Some empirical justifications

${ }^{45}$ See also Clarke-Doane (forthcoming a: section 6, and forthcoming b: section 4).

46 Note that it may be bighly non-trivial to show this in either the mathematical or the moral cases, since it may be highly non-trivial to show that our beliefs are safe.

${ }^{47}$ Balaguer is explicit that his purpose is not to justify our mathematical beliefs, but rather to explain their reliability (under the assumption that they are true). See his (1995). 
of our mathematical beliefs, such as Colyvan's, fail to explain their reliability, since-contra Colyvan - they fail to indicate how those beliefs manage to reliably align with the mathematical truths.

Debunkers appear to have confused these challenges. Consider Joyce's fuller account of why genealogical debunking arguments do not threaten our mathematical beliefs. Joyce writes:

There is some evidence that natural selection has provided humans with an inbuilt faculty for simple arithmetic ... [L]et's interpret this as implying that our belief that $1+1=2$ is innate. This $\ldots$ is an eternal and necessary truth, and thus by "hardwiring" such a belief into our brains natural selection takes no risks-it is not as if the environment could suddenly change such that $1+1$ would equal 3 . So does the fact that we have such a genealogical explanation of our simple mathematical beliefs serve to demonstrate that we are unjustified in holding these beliefs? Surely not, for we have no grasp of how this belief might have been selected for ... independent of its truth ... The truth of " $1+1=2$ " is a background assumption to any reasonable hypothesis of how this belief might have come to be innate.

(Joyce 2006: 182)

Joyce claims that "the truth of " $1+1=2$ " is a background assumption to any reasonable hypothesis of how [the belief that $1+1=2$ ] might have come to be innate." The suggestion that the contents of our mathematical beliefs figure into their best explanation helps to answer the justificatory challenge for mathematical realism. It shows, as per the Indispensability Thesis, that the contents of those beliefs figure into the best explanation of our observations (in Harman's sense). But we may be able to show that the contents of our beliefs of a kind, D, figure into their best explanation despite having no idea how those beliefs manage to reliably align with the D-truths. Indeed, in the mathematical case, this seems to be the situation. Hence, the Indispensability Thesis fails to answer the reliability challenge for mathematical realism.

In the other direction, Joyce suggests that mathematical truths are "eternal and necessary." The suggestion that the mathematical truths are necessary helps to answer the reliability challenge for mathematical realism. It shows, assuming the (actual) truth of our mathematical beliefs, that they are sensitive (the claim that the mathematical truths are eternal seems to be redundant, since, if they are necessary, then presumably they are eternal). Joyce also suggests that our "core" mathematical beliefs are innate, implying that we could not have easily had different ones. This suggestion also helps to answer the reliability challenge. It shows, assuming the necessity of their contents, that our "core" mathematical beliefs are safe. But we may be able to show that our D-beliefs are both sensitive and safe despite our inability to show that their contents figure into their best explanation (or, indeed, despite our 
inability to show that their contents figure into the best explanation of any of our observations). Hence, Harman's Objection may not, and, if Modal Security is true, cannot show that the reliability challenge for moral realism is unanswerable.

\subsection{CONCLUSIONS}

I have argued that in order to relevantly explain the reliability of our beliefs of a kind, D, it appears to be neither sufficient nor necessary to show that their contents figure into their best explanation. It follows that the Indispensability Thesis cannot answer the Benacerraf-Field challenge for mathematical realism, and, if Modal Security is true, that Harman's Objection cannot undermine our moral beliefs by showing that the reliability challenge for moral realism is unanswerable (or, indeed, in any other way). The alternative view apparently arises from a confusion of the justificatory and reliability challenges for D-realism-if it does not arise from the false assumption that showing that the contents of our D-beliefs figure into their best explanation helps to show that they are sensitive or safe.

I have not argued that the genealogy of our D-beliefs is irrelevant to the reliability challenge for D-realism. For all that I have argued, a cultural history of our moral or mathematical beliefs could undermine them by showing that we might have easily had different (explanatorily basic) ones-thereby giving us some reason to believe that they are not safe, and so, a fortiori, not both safe and sensitive. ${ }^{48}$ Or perhaps an evolutionary history of those beliefs could help to answer the reliability challenge for moral realism by blocking this possibility. The point has been that whether a genealogy of our D-beliefs aggravates or alleviates the reliability challenge for D-realism is independent of whether it assumes their contents. In order to "explain the reliability" of our D-beliefs it does not suffice to argue that their genealogy assumes their contents, and in order to "debunk" them it does not suffice to argue the opposite. ${ }^{49}$

48 The empirical fact of moral and mathematical disagreement might have the same effect, in which case genealogical speculation would turn out to be unnecessary in this context. For more on disagreements in mathematics, see Clarke-Doane (2014).

${ }_{49}$ Thanks to David James Barnett, Sinan Dogramaci, Hartry Field, Toby Handfield, Colin Marshall, Josh May, Jennifer McDonald, Alex Silk, Jussi Suikkanen, two anonymous referees for Oxford Studies in Metaethics, and to audiences at the University of Birmingham, Columbia University, the University of Cambridge, the University of Oxford, the 2013 Wisconsin Metaethics Workshop, and the 2014 Set Theory of Semantic Theories of Truth \& Metaphysical Basis of Logic (STSTT/MBL) series at the Northern Institute of Philosophy, for helpful feedback. 


\section{References}

Azzouni, J. 1994. Metaphysical Myths, Mathematical Practice: The Ontology and Epistemology of the Exact Sciences. Cambridge: Cambridge University Press.

Balaguer, M. 1995. "A Platonist Epistemology," Synthese 103: 303-25.

Balaguer, M. 1999. "Review of Resnick," Philosophia Mathematica 7: 108-26.

Benacerraf, P. 1973. "Mathematical Truth," Journal of Philosophy 70: 661-79.

Bengson, J. Forthcoming. "Grasping the Third Realm," Oxford Studies in Epistemology.

Berker, S. 2014. "Does Evolutionary Psychology Show That Normativity Is Mind-Dependent?," in J. D'Arms and D. Jacobson (eds.), Moral Psychology and Human Agency: Philosophical Essays on the Science of Ethics. Oxford: Oxford University Press), 215-52.

Boyd, R. 2003a. "Finite Beings, Finite Goods: The Semantics, Metaphysics and Ethics of Naturalist Consequentialism, Part I," Philosophy and Phenomenological Research 66: 505-53.

Boyd, R. 2003b. "Finite Beings, Finite Goods: The Semantics, Metaphysics and Ethics of Naturalist Consequentialism, Part II," Philosophy and Phenomenological Research 67: 24-47.

Brink, D. 1989. Moral Realism and the Foundations of Ethics. New York: Cambridge University Press.

Chihara, C. 1990. Constructability and Mathematical Existence. Oxford: Oxford University Press.

Clarke-Doane, J. 2012a. "Morality and Mathematics: The Evolutionary Challenge," Ethics 122, 313-40.

Clarke-Doane, J. 2012b. "Response to Braddock, Mogensen, and Sinnott-Armstrong-Part II," Ethics at PEA Soup. Available at: <http://peasoup. typepad.com/peasoup/2012/03/ethicsdiscussions-at-pea-soup-justin-clarke-doa nes-morality-and-mathematics-the-evolutionary-challe1.html>.

Clarke-Doane, J. 2014. "Moral Epistemology: The Mathematics Analogy," Noûs 38: $238-55$.

Clarke-Doane, J. Forthcoming a. "What is the Benacerraf Problem?," in F. Pataut (ed.), New Perspectives on the Philosophy of Paul Benacerraf: Truth, Objects, Infinity.

Clarke-Doane, J. Forthcoming b. "Genealogy and Reliability," in N. Sinclair and U. Leibowitz (eds.), Ethics and Explanation.

Colyvan, M. 2007. "Mathematical Recreation versus Mathematical Knowledge," in M. Leng, A. Paseau, and M. Potter (eds.), Mathematical Knowledge. Oxford: Oxford University Press, 109-22.

Darwin, C. 1871. The Descent of Man. New York: Appleton.

Ellis, B. 1990. Truth and Objectivity. Oxford: Basil Blackwell.

Field, H. 1980. Science without Numbers. Princeton: Princeton University Press.

Field, H. 1989. Realism, Mathematics, and Modality. Oxford: Blackwell.

Field, H. 1996. "The A Prioricity of Logic," Proceedings of the Aristotelian Society 96: 359-79. 
Field, H. 2005. "Recent Debates about the A Priori," in T. S. Gendler and J. Hawthorne (eds.), Oxford Studies in Epistemology, Volume 1. Oxford: Oxford University Press, 69-88.

Gibbard, A. 2003. Thinking How to Live. Cambridge, MA: Harvard University Press. Gödel, K. 1947. "What is Cantor's Continuum Problem?” Revised and reprinted in P. Benacerraf and H. Putnam (eds.), Philosophy of Mathematics. Englewood Cliffs, NJ: Prentice-Hall, 1964.

Harman, G. 1977. The Nature of Morality: An Introduction to Ethics. New York: Oxford University Press.

Hart, W. 1996. "Introduction," in W. Hart (ed.), The Philosophy of Mathematics. Oxford: Oxford University Press.

Hawthorne, J. 2006. Metaphysical Essays. Oxford: Oxford University Press.

Heller, M. 1990. The Ontology of Physical Objects: Four-Dimensional Hunks of Matter. New York: Cambridge University Press.

Hellman, G. 1989. Mathematics Without Numbers. Oxford: Oxford University Press.

Horgan, T. 1987. "Discussion: Science Nominalized Properly," Philosophy of Science 54: 281-2.

Joyce, R. 2001. The Myth of Morality. Cambridge: Cambridge University Press.

Joyce, R. 2006. The Evolution of Morality. Cambridge, MA: MIT Press.

Joyce, R. 2008. "Precis of Evolution of Morality and Reply to Critics," Philosophy and Phenomenogical Research 77: 213-67.

Joyce, R. Forthcoming. "Evolution, Truth-Tracking, and Moral Skepticism," in B. Reichardt (ed.), Problems of Goodness: New Essays on Metaethics. Draft available at: <http://personal.victoria.ac.nz/richard_joyce/onlinepapers.html>.

Korman, D. 2011. "Ordinary Objects," The Stanford Encyclopedia of Philosophy (Winter Edition), ed. Edward N. Zalta. Available at: <http://plato.stanford.edu/ entries/ordinary-objects/>.

Korman, D. 2014. "Debunking Perceptual Beliefs about Ordinary Objects," Philospoher's Imprint 14: 1-21.

Merricks, T. 2001. Objects and Persons. Oxford: Clarendon Press.

Nozick, R. 1981. Philosophical Explanations. Oxford: Oxford University Press.

Pritchard, D. 2008. "Safety-Based Epistemology: Whither Now?," Journal of Philosophical Research 34: 33-45.

Putnam, H. 1971. The Philosophy of Logic. New York: Harper \& Row.

Quine, W. V. O. 1951. "Two Dogmas of Empiricism," Philosophical Review 60: 20-43.

Quine, W. V. O. 1986. "Reply to Charles Parsons," in L. E. Hahn and P. A. Schilpp (eds.), The Philosophy of W. V. Quine. La Salle, IL: Open Court, 396-403.

Ross, W. D. 1939. Foundations of Ethics. Oxford: Oxford University Press.

Ruse, M. 1986. Taking Darwin Seriously. Oxford: Blackwell.

Schecther, J. 2010. "The Reliability Challenge and the Epistemology of Logic," Philosophical Perspectives 24: 437-64.

Sider, T. 2001. Four-Dimensionalism. Oxford: Oxford University Press.

Sinnott-Armstrong, W. 2006. Moral Skepticisms. Oxford: Oxford University Press.

Steiner, M. 1973. "Platonism and the Causal Theory of Knowledge," Journal of Philosophy 70: 57-66. 
Street, S. 2006. “A Darwinian Dilemma for Realist Theories of Value," Philosophical Studies 127: 109-66.

Street, S. 2008. "Reply to Copp: Naturalism, Normativity, and the Varieties of Realism Worth Worrying About," Philosophical Issues 18, 207-228.

Street, S. n.d. "Objectivity and Truth: You'd Better Rethink It." Available at: <https:// files.nyu.edu/ss194/public/sharonstreet/Writing.html>.

Sturgeon, N. 1985. "Moral Explanations," in D. Copp and D. Zimmerman (eds.), Morality, Reason, and Truth: New Essays on the Foundations of Ethics. Totowa, NJ: Rowman and Allanheld, 49-78.

Sturgeon, N. 1986. "Harman on Moral Explanations of Natural Facts," The Southern Journal of Philosophy (Supplement) 24: 69-78.

Van Inwagen, P. 1990. Material Beings. Ithaca, NY: Cornell University Press. 